\title{
Tensile Properties of Durian Skin Fibre Reinforced Plasticized Polylactic Acid Biocomposites
}

\author{
Hazleen Anuar, Mohd Syafiq Razali, Hafizul Adzim Saidin, Ammelia Fazlina Badrul Hisham, \\ Siti Nur E'zzati Mohd Apandi, Fathilah Ali
}

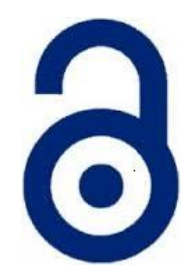

Received: 09 September 2016

Accepted: 26 September 2016

Published: 28 September 2016

Publisher: Deer Hill Publications

(c) 2016 The Author(s)

Creative Commons: CC BY 4.0

\begin{abstract}
This research investigates the effects of plasticizer and durian skin fibre (DSF) loading on tensile and morphological properties of polylactic acid (PLA) biocomposites. Epoxidized palm oil (EPO) was added as a plasticizer in this project. The effect of EPO content $0-10 w t \%$ was investigated over the tensile properties of PLA. EPO at 5 wt $\%$ was found to provide the highest tensile properties on PLA biocomposite. The plasticized PLA was then investigated for the effect of DSF content by varying the DSF at 1, 3 and $5 \mathrm{wt} \%$. The tensile properties improved by about $7 \%$ with 3 wt $\%$ DSF. Scanning electron micrograph revealed that a ductile failure was induced in PLA composite with 5 wt $\%$ EPO and $3 w t \%$ DSF.
\end{abstract}

Keywords. Durian skin fibre, epoxidised palm oil, polylactic acid, tensile properties, ductile failure

\section{INTRODUCTION}

To preserve planet for next generation, the use of natural fibre polymer composites is receiving great attention in food packaging industry. The synthetic polymer based materials lead to an excessive waste in landfill in long period to degrade and also risk the environment and raised the public concern [1]. In 2014, Department of Environment, Malaysia reported that the highest percentage of waste $(\sim 56 \%)$ accumulated in Malaysia is dominated by wastage dumped into landfills to decompose rather than through recycling or incineration.

Therefore, there is a need to reduce these plastic waste problems particularly in food packaging materials [2]. Biodegradable natural fibre-polymer composite is an alternative for food packaging offering range of functional due to their excellent properties in biodegradability, biocompatibility and edible [3]. Despite of the excessive wastage, the increased number of diseases owing to food-borne pathogenic microorganisms in recent years also shows their influence associated with the development in packaging technologies [4]. Therefore, the design concept of active food packaging as the most promising technology systems should be possessing effective attributes towards the preservation quality of food and environment [5]. An active packaging is well defined to extend shelf-life of foods by inhibit microbial growth and maintain the quality of the product with fresh and safe [6].

Plasticizers are important agent in the processing of PLA composites. PLA may improve the brittleness of PLA via polymers chain flexibility and process ability by lowering the second order transition temperature, the glass transition temperature $\left(T_{g}\right)$. Due to low molecular weight and non-volatile compounds in the plasticizers, other properties will be indirectly affected. This includes reduce the tension of deformation, viscosity, hardness and at the same time resistance to biological degradation. Current trends nowadays are utilization of natural-based plasticizers from plants to meet product quality and specification requirements. Palm oil for example is a favourable vegetable oil because it is cheap, low in toxicity and easily available as a sustainable agricultural resource. The effect of epoxidized palm oil (EPO) on PLA/PCL was studied by [7]. They reported that EPO reduced the tensile strength and modulus of PLA/PCL blend produced via solution casting.

This paper investigates the effects of plasticizer and durian skin fibre content on the tensile properties of polylactic acid biocomposites. The scanning electron micrograph is also presented to support the arguments in tensile properties.

\section{H. Anuar et al. $\bowtie$}

Department of Manufacturing and Materials Engineering

International Islamic University Malaysia

PO Box 10, 50728 Kuala Lumpur, Malaysia

E-mail: hazleen@iium.edu.my

Reference: Hazleen et al. (2016). Tensile Properties of Durian Skin Fibre Reinforced Plasticized Polylactic Acid Biocomposites. International Journal of Engineering Materials and Manufacture, 1(1), 16-20. 


\section{EXPERIMENTAL METHOD}

The specimens were prepared via solution casting. The PLA blends were dried in an oven at temperature $80^{\circ} \mathrm{C}$ for $24 \mathrm{~h}$. Biocomposite based on PLA and durian skin fibre were weighed according to the percentage of composite from $1 w t \%$ of DSF content to $5 w t \%$.

Polylactic acid (PLA) was added with chloroform to dilute the PLA powder for solution casting process. The ratio of the chloroform and the PLA was 5:1. The mixture was then stirred with strong agitation of magnetic stirrer until the accumulation of the compound disappeared. For the effect of plasticizer, epoxidized palm oil was added into PLA biopolymer. The EPO was added with amount of $5 \mathrm{wt} \%$ and $10 \mathrm{wt} \%$. The solution is poured into a mold with flat surface of the bottom part. Then, the solution was let for drying at room temperature for $24 \mathrm{~h}$. In the case of the effect of DSF content, the DSF was varied from $0 \mathrm{wt} \%$ to $5 \mathrm{wt} \%$. The DSF and PLA powder were mixed and stirred with spatula to ensure there is not aggregates of the compounds.

Then, all the sample was then cut in specific size for tensile test according to ASTM D882. Tensile test was carried out on Shimadzu Autograph AGS-X series. The cross head speed was $20 \mathrm{~mm} / \mathrm{min}$ and load applied was $5 \mathrm{kN}$. The targeted thickness of the specimen was $0.1 \pm 0.05 \mathrm{~mm}$.

\section{EFFECT OF EPO ON TENSILE PROPERTIES PLAVDSF COMPOSITE}

The effect of epoxidized palm oil (EPO) on the tensile properties of PLA from 0, 5 and 10 wt\% is shown in Fig. 1(a). It is clear from Fig. 1 that the PLA without any EPO have the highest tensile strength with $26.0 \mathrm{MPa}$. PLA with 10 wt\% EPO have the lowest tensile strength which is with $10.6 \mathrm{MPa}$ while PLA with $5 \mathrm{wt} \%$ EPO showed intermediate tensile strength between 0 and $10 \mathrm{wt} \%$ EPO, which is $15.6 \mathrm{MPa}$. Tensile fracture specimen of plasticized PLA at 5 $w t \%$ EPO is shown in Fig. 4(a). Fig. 1 shows that adding more plasticizer (EPO) proportionally decreased the tensile strength of PLA. This finding can be explained by the theory of gelation where the presence of the plasticizer weakened the polymer structure thus improves the flexibility of the PLA biopolymer [8]. The low weight of molecular plasticizer molecules reduced and disrupted the polymers interaction which makes the polymer chain hold together [9-10].

The tensile modulus of PLA/DSF is shown in Fig. 1(b). Generally, the addition of epoxidized palm oil (EPO) as plasticizer was done to improve the tensile properties of rigid PLA. As seen in Fig. 1(a), PLA with 5 wt\% EPO possessed the highest tensile modulus which is $1127.1 \mathrm{MPa}$. PLA with EPO 0 and $10 \mathrm{wt} \%$ again resulted in low tensile modulus. Thus, from Fig. 1 (b), PLA with 5 wt\% EPO will be used for further investigations in terms of reinforcement loading and anti-microbial properties of PLA composites. The increase in tensile modulus is due to good interaction between reinforcement and matrix in increasing wettability property of fibres [11-12]. Results demonstrate that modifying chemical structure of PLA polymer and DSF enhances the compatibility of hydrophilic DSF reinforcement and hydrophilic PLA material in this experiment.
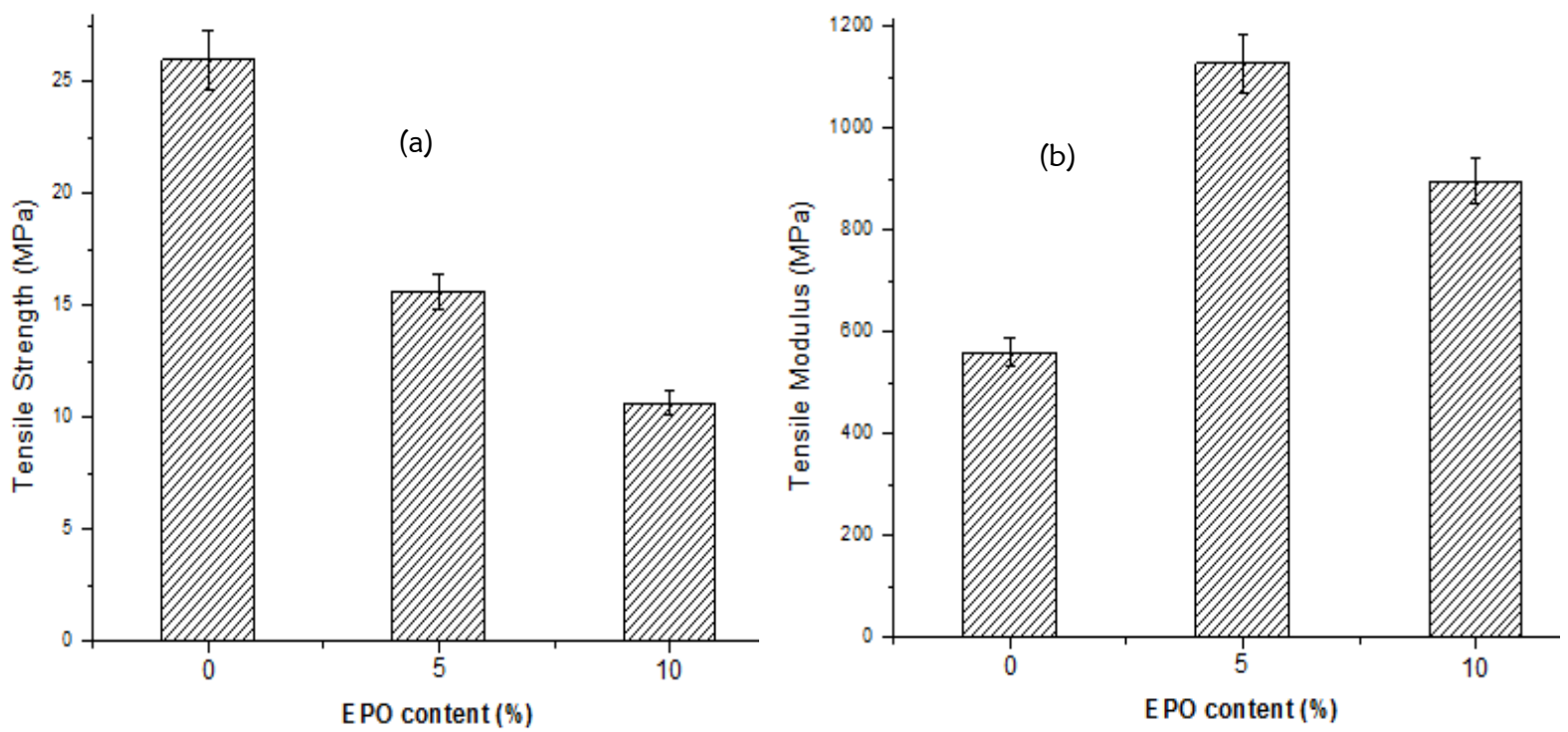

Figure 1: Effect of EPO content of PLA composites on (a) tensile strength and (b) tensile modulus 


\section{EFFECT OF DSF LOADING ON PLA COMPOSITES}

The effect of durian skin fibre (DSF) loading on tensile strength of PLA and plasticized PLA is shown in Fig. 2. From Fig. 2, it can be seen that the presence of DSF from $1 w t \%, 3 w t \%$ and $5 w t \%$ altered the tensile properties of PLA. According Fig. 2 (a), the highest tensile strength was shown by PLA with 3 wt\% DSF. This is due to the strong interaction of interfacial bonding between the PLA matrix and DSF. Beyond $3 \mathrm{wt} \%$, the tensile strength significantly dropped by almost $12 \%$. This is due to the poor interaction which is mainly because of the hydrophobicity of PLA and hydrophilicity of DSF. PLA has an even electrons distribution which makes it non-polar, thus it cannot attract water [12]. The reduction of the strain of the composites is also due to the poor interfacial adhesion between DSF and the PLA matrix as shown in Fig. 3. Fig. 3 shown the stress-strain curve of PLA and PLA/DSF. Fig. 4(a), 4(b) and 4(c) presented micrographs of PLA composites. From Fig. 4(a), the surface of PLA seen more brittle than Fig. 4(b) and $4(\mathrm{c})$. Whereas, ductile failure of the matrix clearly demonstrated the effect of EPO as shown in Fig. 4(c).

The tensile modulus in Fig. 2(b) however shows increasing trend with DSF content. This is usually happened in composites that reinforced with hard filler. This shows that DSF has imparted its stiffness to the matrix [13]. Since this composite loses it brittle and weaker in terms of tensile strength, it tends to be stiffer [14-15]. The addition of fibre increases the flexibility of PLA/DSF biocomposites by improve the polymer chain between both phase. Thus, it gained its mechanical property from DSF content.
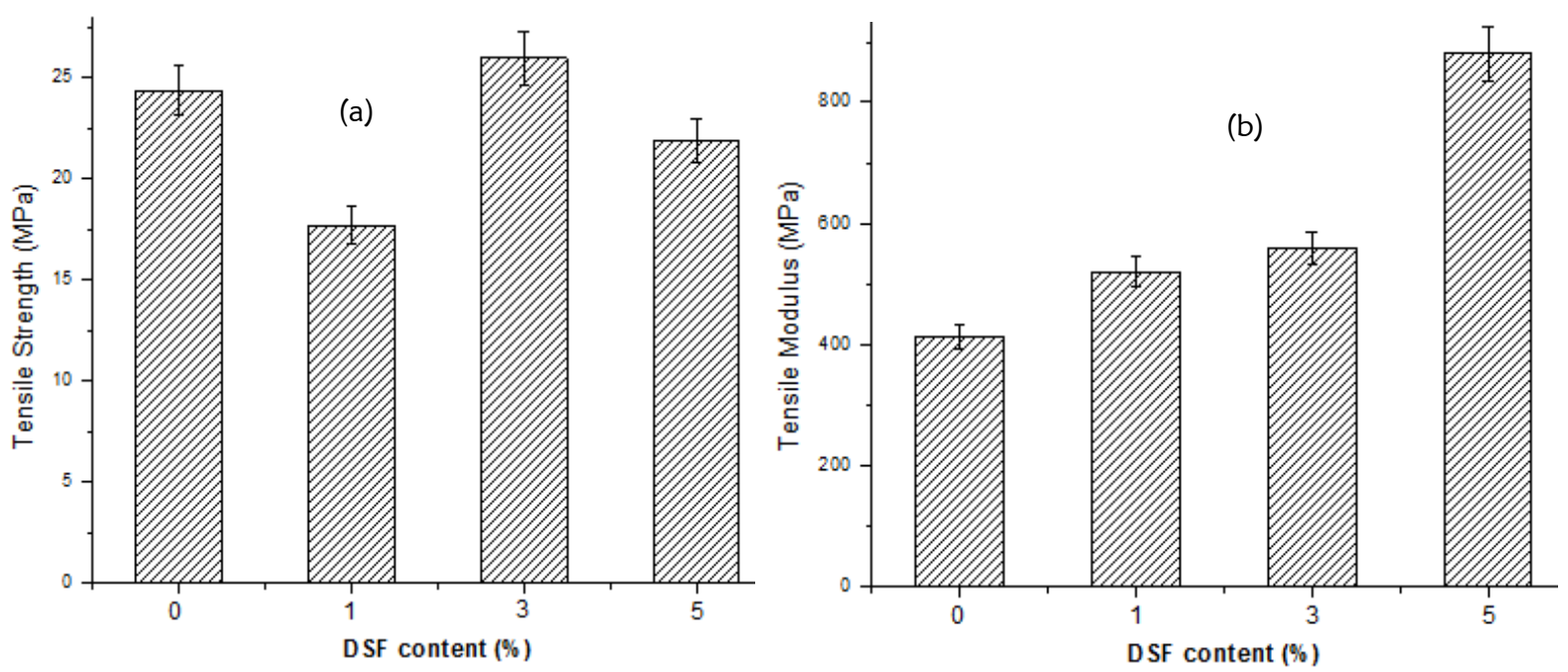

Figure 2: Effect of DSF content of PLA composites on (a) tensile strength (b) tensile modulus

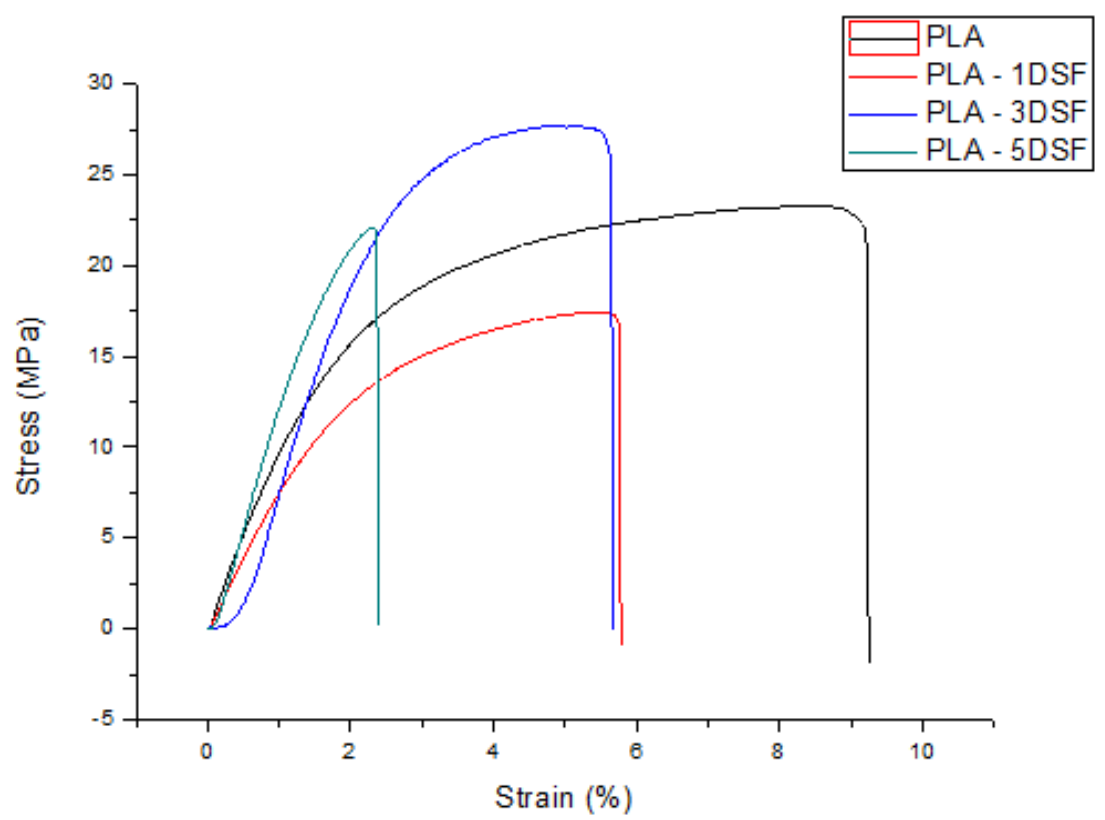

Figure 3: Stress-strain curve of PLA and PLA/DSF composites. 

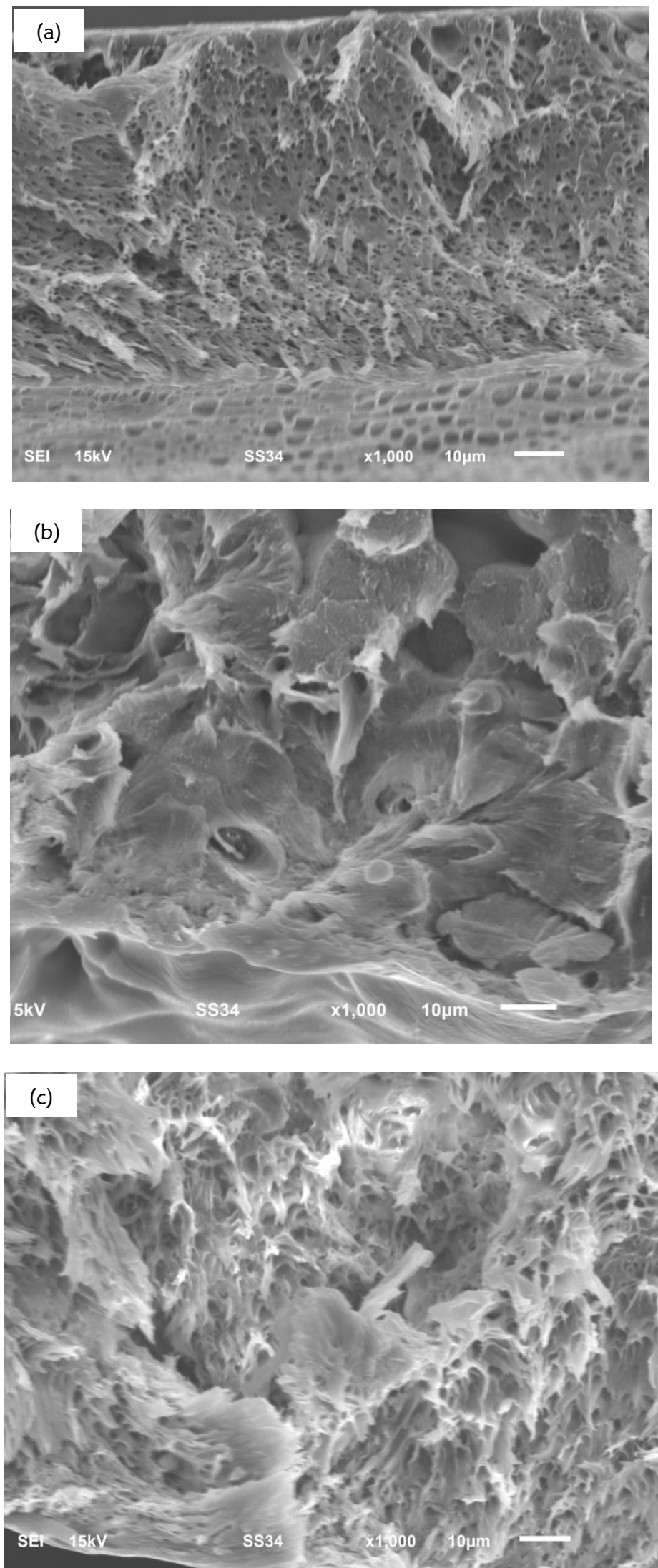

Figure 4: SEM micrographs of tensile fracture specimens at 1000x magnification (a) PLA, (b) PLA/DSF and (c) PLA/DSF/EPO 


\section{CONCLUSIONS}

This research presents the effects of plasticizer and durian skin fibre (DSF) loading on tensile and morphological properties of polylactic acid (PLA) biocomposites with epoxidized palm oil (EPO) as a plasticizer. The prepared composite sample of specific size were tested for tensile test according to ASTM D882 using Shimadzu Autograph ACS-X series (Shimadzu, Japan) with $20 \mathrm{~mm} / \mathrm{min}$ cross head speed and $5 \mathrm{kN}$ load. This experimental research showed the followings.

- The optimum plasticizer needed to plasticize the PLA is found to be $5 \mathrm{wt} \%$.

- The presence of DSF improved tensile properties of plasticized PLA at $3 w t \%$.

- $\quad$ The positive effects of EPO and DSF produced ductile failure of PLA composite.

\section{ACKNOWLEDGEMENT}

This work was financially supported by Fundamental Research Grant Scheme (FRGS16-003-0502) from Ministry of Education Malaysia. The authors would like to thank IIUM for research facilities in making this studies success.

\section{REFERENCES}

1. Neelamana, I. K., Thomas, S., \& Parameswaranpillai, J. (2013). Characteristics of banana fibers and banana fiber reinforced phenol formaldehyde composites-macroscale to nanoscale. Journal of Applied Polymer Science, 130(2), 1239-1246.

2. Janjarasskul, T., \& Krochta, J. M. (2010). Edible packaging materials. Annual Review of Food Science and Technology, 1, 415-448.

3. Salmieri, S., \& Lacroix, M. (2006). Physicochemical properties of alginate/polycaprolactone-based films containing essential oils. Journal of Agricultural and Food Chemistry, 54(26), 10205-10214.

4. Sung, S. Y., Sin, L. T., Tee, T. T., Bee, S. T., Rahmat, A. R., Rahman, W. A. W. A., \& Vikhraman, M. (2013). Antimicrobial agents for food packaging applications. Trends in Food Science \& Technology, 33(2), 110-123.

5. Cagri, A., Ustunol, Z., \& Ryser, E. T. (2004). Antimicrobial edible films and coatings. Journal of Food Protection, 67(4), 833-848.

6. Labuza, T. P., Breene, W.M. (1989). Application of active packaging for improvement of shelf-life and nutritional quality of fresh extended shelf-life foods. Journal of Food Processing and Preservation, 13(1), 1-69.

7. Chieng, B. W., Ibrahim, N. A., Then, Y. Y., \& Loo, Y. Y. (2014). Epoxidized vegetable oils plasticized poly (lactic acid) biocomposites: mechanical, thermal and morphology properties. Molecules, 19(10), 16024-16038.

8. Mekonnena, T., Mussone, P., Khalil, H., \& Bressler, D. (2013). Progress in bio-based plastics and plasticizing modifications. Journal of Materials Chemistry A, 1(43) 13379-13398.

9. Xu, Y. Q., \& Qu, J. P. (2009). Mechanical and rheological properties of epoxidized soybean oil plasticized poly (lactic acid). Journal of Applied Polymer Science, 112(6), 3185-3191.

10. Smith, E. R., Howlin, B. J., \& Hamerton, I. (2013). Using POSS reagents to reduce hydrophobic character in polypropylene nanocomposites. Journal of Materials Chemistry A, 1(41), 12971-12980.

11. Hargitai, H., Rácz, I., \& Anandjiwala, R. D. (2008). Development of hemp fiber reinforced polypropylene composites. Journal of Thermoplastic Composite Materials, 21(2), 165-174.

12. Tee, Y. B., Talib, R. A., Abdan, K., Chin, N. L., Basha, R. K., \& Yunos, K. F. M. (2015). Comparative Study of Chemical, Mechanical, Thermal, and Barrier Properties of Poly (Lactic Acid) Plasticized with Epoxidized Soybean Oil and Epoxidized Palm Oil. BioResources, 11(1), 1518-1540.

13. Nazri, W. B., Ezdiani, Z. N., Romainor, M. M., Erma, K. S., Jurina, J., \& Fadzlina, N. (2014). Effect of durian skin fibre loading on the mechanical properties. Journal of Tropical Agriculture and Food Science, 42(2), 169.

14. Faruk, O., Bledzki, A. K., Fink, H. P., \& Sain, M. (2012). Biocomposites reinforced with natural fibers: 20002010. Progress in polymer science, 37(11), 1552-1596.

15. Xiao, L., Wang, B., Yang, G., \& Gauthier, M. (2012). Poly (lactic acid)-based biomaterials: synthesis, modification and applications (pp. 247-282). INTECH Open Access Publisher. 